\title{
0 que é o Ocidente?
}

\section{Vera Santos}

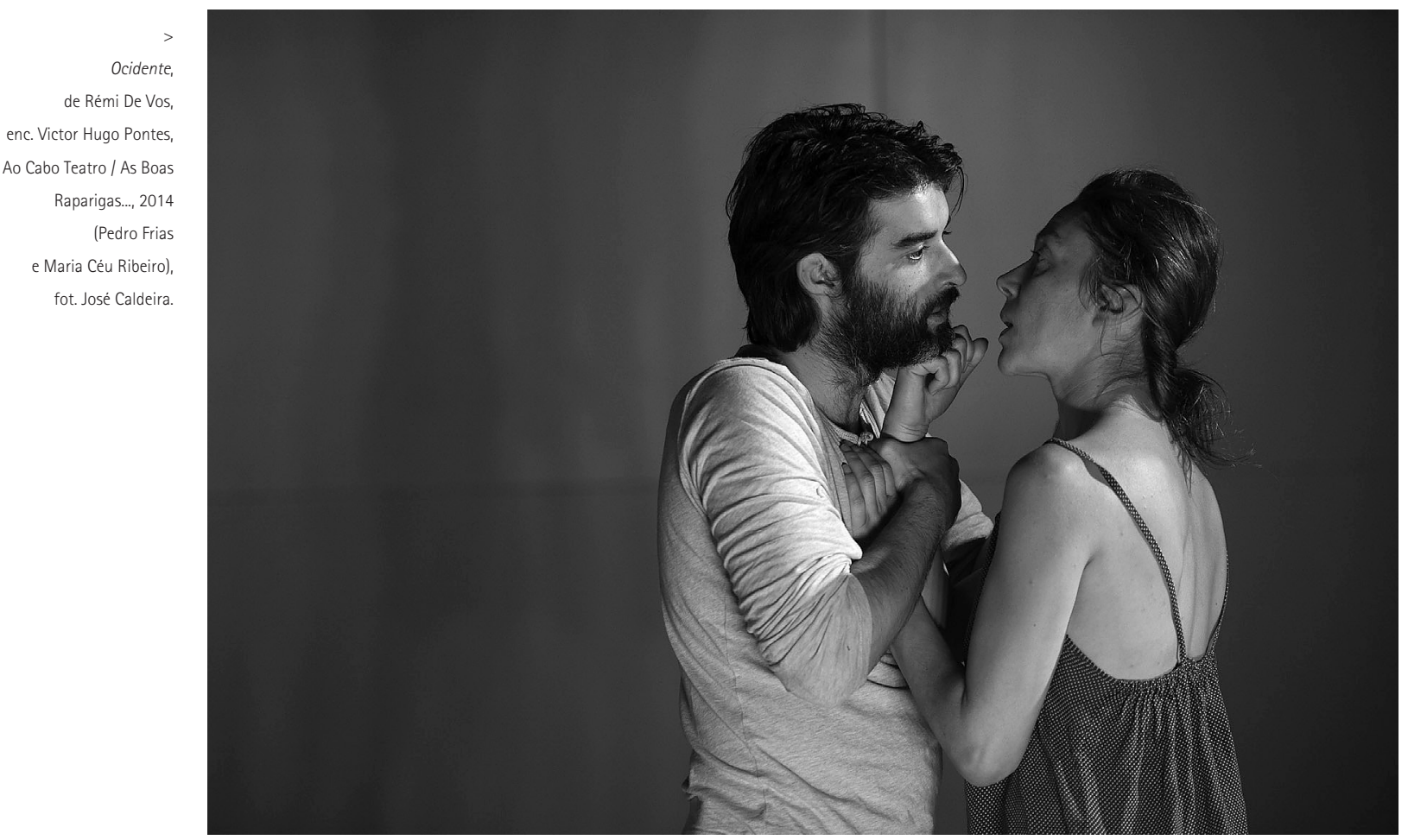

Titulo: Ocidente (Occident, 2005). Autor: Rémi De Vos. Tradutora: Regina Guimarães. Encenador: Victor Hugo Pontes. Cenografia: F. Ribeiro. Desenho de luz: Wilma Moutinho. Desenho de som: Luis Aly. Piano (banda sonora): Pedro Frias. Interpretação: Maria do Céu Ribeiro e Pedro Frias. Co-produção: Ao Cabo Teatro / As Boas Raparigas... / Centro Cultural Vila Flor. Local e data de apresentação: TeCA, Porto, 9 de Maio de 2014.

A caminho de Lisboa para iniciar uma nova criação, desta feita para crianças, Victor Hugo Pontes conta-me a história desta encenação. Começa em 2007, quando estava em Bussang (França) a trabalhar como actor num projecto no Théâtre du Peuple. Ali assistiu à leitura de excertos de Occident com a presença do autor, Rémi De Vos. Victor Hugo estava alojado na casa da actriz que participou nesta

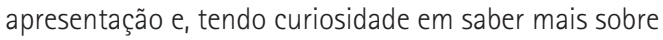
o texto, pediu-Ihe para aceder à peça integral. Desta leitura surgiu uma ideia de encenação, que não é a que acabou por desenvolver, mas a centralidade das palavras

Vera Santos é bailarina, pedagoga e investigadora. Licenciada em História de Arte e Mestre em

Estudos artisticos/ teoria e critica de arte pela Universidade do em Outubro, na Fábrica ASA, em plena ressaca da Guimarães Capital Europeia da Cultura. Em Maio de 2014, Ocidente chega ao Teatro Carlos Alberto no Porto. Tratase da quarta encenação deste reconhecido coreógrafo que, depois de Susan Sontag (em 2007), Simon Stephens (em 2011) e JP Simões (em 2012), se encontra com as palavras de Rémi De Vos.

Victor Hugo Pontes movimenta-se entre o teatro, a dança, as artes plásticas, o vídeo e a imagem fotográfica. Tem a particularidade de compor com subtis contaminações das diferentes linguagens na medida exacta com que define o objecto que cria. A lógica sequencial das suas criações não é fácil de definir (a não ser pelo próprio), uma vez que advém dos lugares e das pessoas com que se cruza, das vivências pessoais e até dos medos, sem contudo, se tratar de um trabalho autobiográfico. 0 seu percurso pessoal faz a sua carreira artística, e a sua carreira artística condiciona o seu percurso pessoal.

A encenação de Ocidente segue o texto sem didascálias (senão breves indicações de tempo) e utiliza-o na íntegra, 


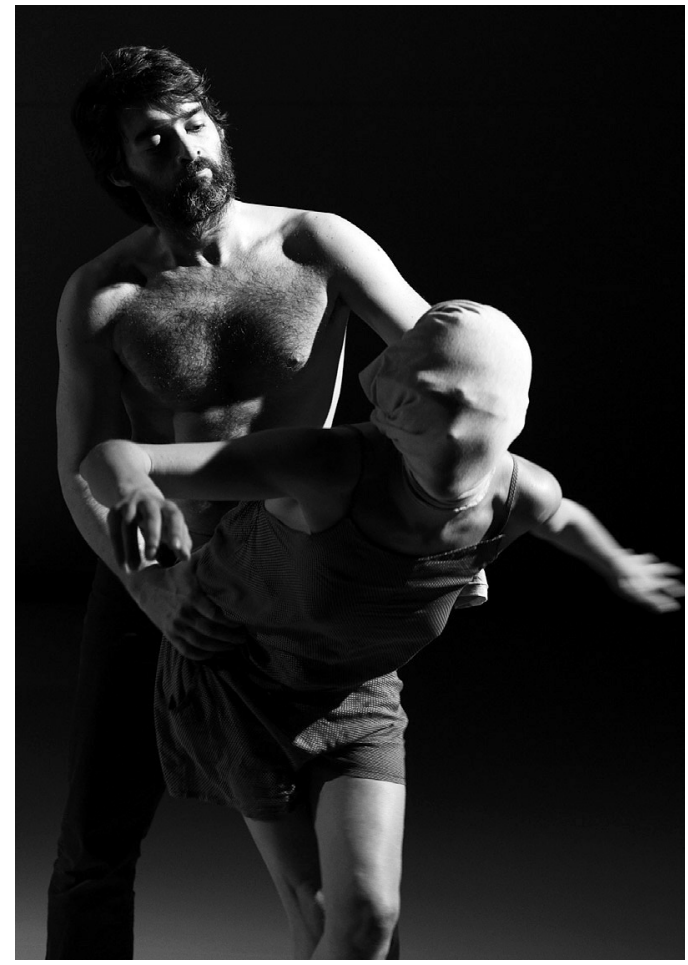

com a tradução de Regina Guimarães a fazer-nos ouvir palavras que soam incomuns quando articuladas num diálogo tão corpo a corpo - mas é talvez isso que nos impede de cair numa "novela". Porque as palavras nos levam para lá de onde o corpo chega e onde muitas vezes não queremos ir. É uma narrativa aberta, que não apresenta soluções para muitas das situações que ocorrem, e a encenação deixa-a também assim. Ao telefone, o encenador explica que "mesmo durante o processo, não foram reveladas as soluções que os actores encontraram, não há conhecimento mútuo das razões. Trata de uma história de amor". Victor Hugo Pontes considera que eles falam como forma de manter a relação.

A cenografia (assinada por F. Ribeiro) é um apontamento de parede suspensa, inclinada (em queda ou a meio de ser erguida), com um vão rasgado, uma janela que estabelece um "lado de lá" onde ficam o Palace, o Flandres, o Mohamed, os Jugoslavos, os Árabes, e um "lado de cá" onde estamos nós. Um colchão como colchão, mas objecto deslocado, no chão, nem sempre cama, por vezes corpo, por vezes bóia de naufrágio, como símbolo de intimidade, como referência de interior, mas também de abandono de sem abrigo (sem lugar para onde ir). Tudo isto se esclarece pelas palavras, quando, por exemplo, Ela diz: "Queres que a gente vá para o quarto?".

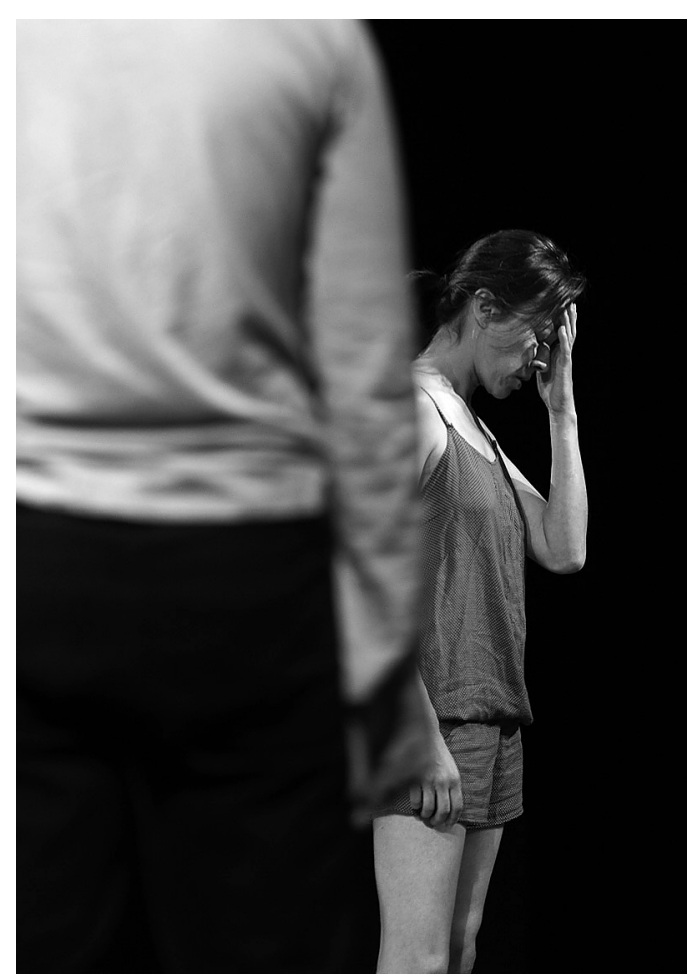

Ocidente,

de Rémi De Vos,

enc. Victor Hugo Pontes, Ao Cabo Teatro / As Boas Raparigas..., 2014 (Pedro Frias e Maria Céu Ribeiro), fot. José Caldeira.
"Stop!" é a palavra de comando que Ela usa como quem domina um jogo erótico. Mas será masoquista? 0 espaço transforma-se em ringue de boxe, enche-se de destroços a cada round e, de cada vez que Ele vai ao canto, o vazio adensa-se e as ruínas crescem. A opção de sair é enunciada, mas não há porta, pelo que a saída pela morte talvez seja a única possível e talvez estejamos perante esse facto consumado. É nesse lugar sem referências que Ela (uma Europa raptada por Zeus) está cansada, desfalece e quer voltar a ver o mar.

Estes corpos não são os das personagens da mitologia grega, mas a forma como a encenação gere a tensão entre eles, e como a luz (de Wilma Moutinho) nos deixa ver esse campo magnético e de extermínio. A densidade, com que operam este texto rarefeito, faz-nos pensar que a eternidade se vive assim. A realidade, tal como a conhecemos, não suporta este ritmo, esta ambiguidade, estes silêncios e as próprias afirmações. Nada se assemelha à realidade, mas tudo nos remete para ela. É o som que abre brechas nesta peça - no terreno que pisam, Ela descalça e Ele de sapatos - levando-nos de volta ao lugar de espectadores conduzidos.

0 Ocidente é um ponto cardeal que fica à nossa frente, quando temos o Norte à direita, e por horizonte o mar onde o sol se põe. 